\title{
A BNCC E A FORMAÇÃO: \\ Expectativas e Possibilidades Diante da Reforma do Novo Ensino Médio
}

\author{
Eduardo Cardoso do Socorro ${ }^{1}$ \\ Rejane Lima de Queiroz ${ }^{2}$
}

\section{Resumo}

Este artigo apresenta reflexões sobre o novo ensino médio e os itinerários formativos; discutindo sobre os entraves e expectativas da escola e o currículo; as tecnologias educacionais; e um paralelo entre o professor que a escola tem e o professor que o novo ensino médio quer.Ao trilhar os caminhos da educação começando pela história da educação brasileira percebe-se que a profissão de professor inicialmente teve como base pressupostos religiosos e políticos. Atualmente os recintos escolares apresentam um contexto sociocultural diversificado e é nesse espaço que os docentes atuam tornado o processo de ensino aprendizagem bastante significativo por isso faz-se necessário à construção de um currículo que represente o espaço no qual estão inseridos. A metodologia utilizada para realizar esta pesquisa foi a pesquisa bibliográfica com pesquisas em livros, revistas, artigos e material na internet. Conclui-se que a formação continuada para os professores contribui para a melhoria da qualidade de ensino existe uma preocupação com a formação dos professores e com a sua prática por conta da atual conjuntura social do país que tem interferindo de forma significativa no contexto escolar. Pois o perfil do professor delineado para atuar no Novo Ensino Médio é o de ter a formação básica desejável em licenciatura na área de atuação.

Palavras Chave: Formação Continuada. Metodologia. Docente. Ensino Médio.

\begin{abstract}
This article presents reflections on the new high school and training itineraries; discussing the school's barriers and expectations and the curriculum; educational technologies; and a parallel between the teacher that the school has and the teacher that the new high school wants. When walking the paths of education starting with the history of Brazilian education it is clear that the profession of teacher was initially based on religious and political assumptions. Currently, school premises present a diversified socio-cultural context and it is in this space that teachers act, making the teaching-learning process quite significant, so it is necessary to build a curriculum that represents the space in which they are inserted. The methodology used to carry out this research was bibliographic research with searches in books, magazines, articles and material on the internet. It is concluded that the continuous training for teachers contributes to the improvement of the quality of teaching there is a concern with the training of teachers and with their practice due to the current social situation in the country that has significantly interfered in the school context. Because the profile of the teacher designed to work in the New High School is to have the desirable basic training in undergraduate in the area of expertise.
\end{abstract}

Keywords: Continuing Education. Methodology. Teacher. High school.

\footnotetext{
${ }^{1}$ Mestre em Ciências da Educação pela Faculdade Interamericana de Ciências Sociales (FICS). Pósgraduado em Metodologia do Ensino Superior (UNEB). Pós-graduado em Gestão Educacional (FBS).Licenciado em Geografia pela Universidade Católica do Salvador. Bacharel em Direito pela Faculdade Dois de Julho.. Atua como Advogado e Professor de Geografia na Rede Estadual de Ensino do Estado da Bahia.Email:edwjazz@hotmail.com

${ }^{2}$ Mestre em Ciências da Educação pela Faculdade Interamericana de Ciências Sociales (FICS). Pósgraduada em: Estudos Linguísticos e Literários pela UFBA; Educação, Desigualdade e Pobreza (UFBA); Gestão em Saúde (UNILAB) e Gestão Educacional pela (FFB).Licenciada em Letras Vernáculas pela Universidade Estadual de Feira de Santana (UEFS) Bacharela em Serviço Social Universidade Salvador (UNIFACS).. Atua como professora de Língua Portuguesa na rede estadual dos municípios de São Francisco do Conde e Candeias, Bahia. Email:rejanequeiroz75@gmail.com
} 


\section{Introdução}

Recentemente os debates em torno do ensino médio foram retomados além da implementação da Base Nacional Curricular Comum (BNCC) contendo uma reforma para o ensino médio $\mathrm{E}$ neste bojo para atender as demandas apresentadas para a adequação da BNCC aponta-se a relevância da formação continuada docente para atender o Novo Ensino Médio.

Ao abordar a temática da formação continuada em serviço do professor para - Novo Ensino Médio necessariamente adentraremos em sua função, os procedimentos formativos, o desenvolvimento do profissional e por consequência as práticas pedagógicas (MARIN, 2005). O assunto da formação continuada tem se mostrado tão relevante que passou a ser alvo de políticas públicas educacionais e despertou o interesse de diversos autores como Paulo Freire, Vera Candau, Francisco Imbernón, Selma Garrido Pimenta, Bernadete Gatti entre outros

Todos esses estudiosos e especialistas nas diversas áreas de conhecimento do seguimento educacional vêm se debruçando sobre a temática formação continuada docente e produzindo inúmeras obras com múltiplos olhares nos últimos vinte cinco anos. Diante destas concepções justifica-se esta investigação para compreender os entraves para uma formação continuada e em serviço dos docentes, levando em consideração as especificidades do Novo Ensino Médio.

A formação continuada em serviço para o professor do Novo Ensino Médio é de grande relevância para a melhoria da práxis pedagógica docente, mas alguns autores abordam que a formação continuada como complementação da formação inicial do professor é insuficiente e por isso defendem a reforma do currículo dos cursos de licenciaturas por parte das universidades (GASPARIAN, 2011).

A formação continuada precisa ser concebida não apenas como forma de melhoria da qualidade de ensino, mas também como valorização do professor; ampliação dos conhecimentos; forma de agregar saberes e reflexão sobre a sua ação implicando na reavaliação da prática pedagógica.

\section{O Novo Ensino Médio e os Itinerários Formativos}

A lei 13.415/2017 trouxe modificações para a Lei de Diretrizes e Bases da Educação no que diz respeito à estrutura, carga horária mínima e currículo do Novo Ensino Médio. A discussão e debates em torno do ensino médio é antiga passando por várias alterações após a sua instituição. Interessados pela educação, docentes e 
estudiosos ao longo do tempo sinalizaram a necessidade de modificações para que o segundo grau, o ensino médio atendesse as demandas da atual sociedade.

Recentemente os debates em torno do ensino médio foram retomados e nesses diálogos sugeriu-se uma reforma para o ensino médio na qual seria realizada a construção de uma Base Nacional Curricular Comum (BNCC). Toda essa discussão resultou na organização de vários eventos pelo país como Seminários, Consultas públicas, e aos municípios coube à tarefa de organização e fomento de propostas curriculares. Nesse mesmo ano houve a instituição da Associação Brasileira de Currículo (ABdC), e o Ministério da Educação e Cultura tornar pública a Base Nacional Comum Curricular (BNCC) que é:

\begin{abstract}
Um documento de caráter normativo que define o conjunto orgânico e progressivo de aprendizagens essenciais que todos os alunos devem desenvolver ao longo das etapas e modalidades da Educação Básica, de modo a que tenham assegurados seus direitos de aprendizagem e desenvolvimento, em conformidade com o que preceitua o Plano Nacional de Educação (PNE) (BRASIL, 2018, p.7).
\end{abstract}

A introdução da Base Nacional Curricular Comum (BNCC) no sistema de ensino brasileiro suplantou alguns desafios começando pela igualdade e equidade, estabelecendo condições justas de acesso ao ensino e zelando para que 'todos' aqueles que ingressarem no ensino básico da educação concluam esta etapa e que tenham desenvolvidos as competências e habilidades fundamentais para a próxima etapa de ensino. A BNCC, também pode ser definida como:

Um documento normativo que deverá servir como diretriz para a construção dos currículos das redes públicas e particulares de ensino nas instâncias municipais, estaduais e federais para a educação infantil e anos iniciais do ensino fundamental (CURY, 2018, p.18).

O currículo do Novo Ensino Médio proposto pela BNCC mostra-se bastante flexível e diversificado e vem suplantar o antigo ensino médio. No Novo Ensino Médio o currículo passa a ser formado pela base comum e pelos itinerários formativos ciências da natureza e suas tecnologias; ciências humanas e sociais aplicadas; linguagens e suas tecnologias; matemática e suas tecnologias; e formação técnica e profissional.

Além de estabelecer à divisão em itinerários formativos a lei 13.415/2017 dispõe sobre a carga horária mínima para a educação básica e o ensino médio distribuído por duzentos dias letivos. Pode-se garantir que a Base Nacional Curricular comum é uma política de estado e, portanto mencionada na Constituição 
federal, na Lei de Diretrizes e Bases (LDB) e no Plano Nacional de Educação (PNE). Esses três dispositivos legais garantem o direito de aprender.

Percebe-se que a BNCC consolida-se como um importante documento norteador de ações voltadas para a educação nacional e instrumento de pesquisa e estudo para os apaixonados pela educação e docência. Na outra ponta encontramse a escola, os estudantes e a sociedade que serão essenciais para que ela se efetive e torne-se realidade.

Ao optar pela adoção da Base a escola precisa estar ciente do que é necessário para fazê-la acontecer na prática assim isso se converge no primeiro desafio. O próximo desafio é estabelecer um parâmetro educacional (currículo) que esteja de acordo com o que é exigido pela base e com as necessidades da comunidade na qual a escola está localizada e o terceiro passo diz respeito a aquele que irá executá-la: o professor. A escola precisa construir um planejamento detalhado para que a formação subsidie o professor em conhecimentos para que as dificuldades apresentadas ao longo da implantação do Novo Ensino Médio e no decorrer dele. Esses três desafios iniciais podem constituir-se entraves que poderão comprometer todo o processo educativo escolar.

A adoção da Base Nacional Curricular Comum (BNCC) propõe um grande desafio para a unidade escolar que é a concepção de um currículo que preserve as disciplinas fundamentais e em comum a todas as escolas e o desafio maior é a construção de um currículo que traduza a sua identidade e característica e ao mesmo tempo faça com que esse currículo expresse suas alusões, seja atraente, sedutor capaz de despertar o interesse dos estudantes, mas que, sobretudo não se distancie da cultura e realidade social daquela comunidade escolar. Por isso também é importante e impreterível que o Projeto Político Pedagógico (PPP) seja reformulado e adequado às novas necessidades escolar e exigências da proposta do Novo Ensino Médio.

Para que o currículo não incorra em um entrave e que esteja em acordo com o contexto social, com as aspirações dos estudantes, se enquadre nas normas e identidade escolar é preciso ouvir os principais interessados que no caso aqui são os estudantes, consequentemente a comunidade. De posse das informações necessárias começa-se a esboçar o currículo por toda equipe escolar. Com esboço pronto é importante retornar a comunidade e estudantes para ver se de fato ele atende os anseios de todos. 
É justamente nesse período de discussão que pode-se gerar outros entraves por isso é necessário que alguém assuma o papel de conciliador e aparador das arestas com o intuito de evitar outras possíveis cizânias que podem comprometer todo processo. Ao delinear o currículo é preciso haver definição das propostas, dos conteúdos primordiais de cada série, de cada disciplina os quais serão abordados em sala de aula pelo docente. Espera-se que com essas tomadas de decisões obtenhamos uma melhora na qualidade de ensino o que de certa forma nos leva a diminuir as desigualdades existentes na escala de aprendizado de cada individuo.

Outro desafio advindo do termo de aceite ao Novo Ensino Médio diz respeito ao professor, neste caso à necessidade da formação continuada para que o docente entenda a Base Nacional Curricular Comum (BNCC), a proposta dessa modalidade de ensino e o perfil do profissional que a colocará em funcionamento. Este profissional precisa dar conta de sua função e ainda desempenhar outras para as quais não foram preparados pela academia. Então o que fazer com este professor? Ele terá que voltar a academia?

A escola ao aderir ao Novo Ensino Médio ela precisa instrumentalizar este profissional para dar conta de uma série de questões que virão com o tempo como, por exemplo, a insatisfação com a escolha do Itinerário que vai implicar no rendimento escolar e em outros problemas emocionais. Questionamentos de conteúdos principalmente com as disciplinas de práticas e pesquisas para as quais o docente não foi preparado pela academia. Vale salientar que grande parte dos docentes não teve a oportunidade de trabalhar com o desenvolvimento de pesquisa ao longo da graduação visto que tal fato como é de conhecimento público restringese ao mestrado, doutorado e alguns cursos de graduação (bacharelados).

Ainda sobre as disciplinas de práticas e pesquisa a formação continuada é uma ferramenta real, pois os docentes não estão aparelhados para lidar com essa configuração de ensino inclusive para a produção de conteúdos exigidos para estas disciplinas e sem contar com o uso das tecnologias em sala de aula. Aí incide-se no primeiro desafio concernente a estrutura e aparelhamento da escola.

A BNCC estimula o uso das tecnologias educacionais como uma ferramenta a mais na produção de conhecimento. A quinta competência do referido documento versa justamente para o aspecto de:

Compreender, utilizar e criar tecnologias digitais de informação e comunicação de forma crítica, significativa, reflexiva e ética nas diversas práticas sociais (incluindo as escolares) para se comunicar, acessar e 
disseminar informações, produzir conhecimentos, resolver problemas e exercer protagonismo e autoria na vida pessoal e coletiva (BRASIL, 2018, p.9).

Ressalta-se que apesar da BNCC enfatizar 0 uso de instrumentos tecnológicos pelo professor em sua aula ela abre precedentes ao não determinar de forma precisa como essa introdução deve ser realizada. A escola de forma dialógica e colaborativa precisa manifestar-se indicando caminhos possíveis para seu uso de forma no que diz respeito aos conteúdos estipulados pelo currículo escolar. Possibilitando e impulsionando a aprendizagem no fazer pedagógico ao inserir a tecnologia em sala.

A importância da formação continuada para os professores é vital para revisar e revitalizar as práticas pedagógicas já que a Base Nacional Curricular Comum (BNCC) destaca a importância da formação integral da pessoa, uma vez que:

Reconhece, assim, que a Educação Básica deve visar à formação e ao
desenvolvimento humano global, o que implica compreender a complexidade
e a não linearidade desse desenvolvimento, rompendo com visões
reducionistas que privilegiam ou a dimensão intelectual (cognitiva) ou a
dimensão afetiva. Significa, ainda, assumir uma visão plural, singular e
integral da criança, do adolescente, do jovem e do adulto - considerando-os
como sujeitos de aprendizagem - e promover uma educação voltada ao seu
acolhimento, reconhecimento e desenvolvimento pleno, nas suas
singularidades e diversidades (BRASIL, 2018, p14)

Entende-se que a formação integrada abarca o cognitivo e o sócio emocional. A BNCC determina esses aspectos, o professor é que terá mais essa incumbência de oportunizar o afloramento, o desabrochar sócioemocional de cada indivíduo e, portanto este profissional deve possuir formação e do domínio das ferramentas tecnológicas que por sinal é outro entrave na aplicação da BNCC, pois os docentes em sua maioria ao longo de sua formação acadêmica inicial e ou continuada não foram instrumentalizados e preparados para a lida desses aparatos o que nos conduz a necessidade de atualização das práticas pedagógicas.

\section{A Escola e o Currículo: Entraves e Expectativas}

A nova modalidade e seus itinerários formativos chegam às escolas trazendo consigo muitas inquietações, expectativas e alguns entraves. Questionam-se o espaço físico das unidades escolares, O material didático, a tecnologia, os laboratórios, as salas de aulas, o currículo escolar, a formação para trabalhar com esta modalidade, a carga horária do professor e das disciplinas lecionadas por ele. 
Em meio a tantas indagações começou a ser delineado os caminhos para o Novo Ensino Médio.

Versaremos aqui sobre a escola cuja função precípua é a de possibilitar a obtenção de conhecimentos. É nela que serão desenvolvidas atividades de cunho pedagógico no qual se inserem os conhecimentos fundamentais que corroborarão para o exercício pleno da cidadania.

Os colóquios em torno da proposta da Base Nacional Curricular Comum (BNCC), de forma particular o quesito currículo gera muitas tensões e conflitos, aliás, o assunto em si já é polêmico e quando se reflete sobre o seu conceito e de um currículo escolar que abarque a grandeza nacional comum tanto para as instituições públicas e particulares, onde currículo é "o conjunto de atividades nucleares realizadas na escola" (SAVIANI, 2003, p.12).

A pauta de discussão em torno do currículo levou ao estabelecimento de relação com as políticas (teoria) e as Práticas (ações). A complementaridade entre teoria e prática corroborou para que o objetivo de mudar algo fosse alcançado. Por currículo depreende-se que é:

O conjunto dos vários tipos de aprendizagem, aquelas exigidas pelo processo de escolarização, mas também aqueles valores, comportamentos, atitudes, que se adquirem nas vivencias cotidianas na comunidade, na interação [...] . O currículo, dessa forma, variou conceptualmente de diversas formas na sua historicidade até chegar ao termo atual (LIBÂNEO, 2001, p. 101).

A escola enquanto espaço promoverá esses debates (diálogos) que cooperam para a construção e solidificação do alicerce do conhecimento. Ao refletir sobre as questões nas quais a sociedade está imersa possibilita-se o desenvolvimento da criticidade e valores como empatia, tolerância, respeito, da responsabilidade para uma convivência pacifica e harmônica em sociedade. Faz-se necessário lembrar que:

A educação é um processo de humanização; que ocorre na sociedade
humana com a finalidade explicita de tornar os indivíduos participantes do
processo civilizatório e responsáveis por levá-lo adiante. Enquanto prática
social é realizada por todas as instituições da sociedade. Enquanto processo
sistemático e intencional ocorre em algumas, dentre as quais se destaca a
escola. Educação escolar por sua vez, está assentada fundamentalmente no
trabalho dos professores e dos alunos, cuja finalidade é contribuir com o
processo de humanização de ambos pelo trabalho coletivo e interdisciplinar
destes com o conhecimento, numa perspectiva de inserção social crítica e
transformadora (PIMENTA, 2012, p.24-25)

Sendo a educação dever da família nada mais adequado que a escola grande parceira na instrução dos seus filhos estabeleça condições cômodas ao entendimento e oferta de conhecimentos. Por meio do seu procedimento educativo, 
a escola, propagadora de saberes, formadora de valores e responsável em estabelecer requisitos para que alcance maior equidade social, uma vez que os problemas sociais causam interferência na qualidade de ensino e aprendizagem, uma vez que:

\begin{abstract}
A educação é um processo social amplo que se concretiza nas famílias, nas comunidades e também nas escolas. Porém, histórica e socialmente a instituição gestada ao longo dos séculos para cumprir a função específica de oferecer às crianças $e$ as jovens os conhecimentos estruturados e acumulados no tempo, conhecimentos constituintes da vida e civilização humanas, foi à escola (ANDRÉ, 2016, p.37).
\end{abstract}

Como se pode notar a escola está incumbida de fomentar o desenvolvimento dos conhecimentos básicos necessários para que haja um equilíbrio, uma igualdade entre os estudantes e também por conta do seu aspecto/função social tem o dever de também de fazer com que estes se preparem para a vida, ao mundo do trabalho, à vida em comunidade e uma relação mais respeitosa para com o meio ambiente, à saúde e a participação. A modalidade do Novo Ensino Médio tem como objetivo estabelecer condições iguais e justas para todos os estudantes e, "além disso, a escola, como espaço de aprendizagem e de democracia inclusiva, deve se fortalecer na prática coercitiva de não discriminação, não preconceito e respeito às diferenças e diversidades" (BRASIL, 2018, p.14)

A Base Nacional Curricular Comum (BNCC), e os currículos se identificam na comunhão de princípios e valores que, como já mencionado, orientam a Lei de Diretrizes e Bases (LDB) e as Diretrizes Curriculares Nacionais (DCN). Dessa maneira, reconhecem que a educação tem um compromisso com a formação e o desenvolvimento humano global, em suas dimensões intelectual, física, afetiva, social, ética, moral e simbólica. (lbid., p16)

Atendendo as diretrizes da Base Nacional Curricular Comum (BNCC), o currículo escolar deve se inspirar nos princípios constitucionais adaptando-se a realidade de forma a colocar todos em pé de igualdade, uma vez que "todos são iguais, constituindo-se uma função social do estado cumprindo o atendimento do direito do cidadão que vê na escola uma via de cidadania" (Id., p.19).

Ao refletir sobre o que venha a ser currículo, bem como sua importância para o desempenho e proposta escolar o gestor, a equipe pedagógica, docentes e demais profissionais que integram o quadro escolar não devem e não pode esquecer-se que ele necessita estar ajustado ao contexto no qual se inserem os 
estudantes. Então de precisa-se conhecer a região (localidade) na qual se localiza a escola a fim de compreender os aspectos históricos, culturais, econômicos que a circundam e desta forma se construa um currículo significativo que tenha vínculo, desperte o fascínio e represente os estudantes e que siga as orientações da BNCC.

O currículo deve ser concebido como uma obra que é de interesse de todos devendo refletir a realidade e aspectos identitários da unidade escolar, todavia dificilmente caminhará para o caminho delineado o que provocará reflexões, questionamentos e lutas por que "a educação é o processo pelo qual a sociedade forma seus membros à sua imagem e em função de seus interesses" (PINTO, 1989, p.29). É dentro do contexto educacional, que se encontram diferentes sujeitos, que pertencem a diferentes contextos sociais, que trazem sua historicidade construída a partir de diferentes vivências, assim é possível e faz-se necessário buscar saídas para uma democratização do ensino.

A oferta do Novo Ensino Médio por parte das escolas passa a existir com o objetivo de atender e preencher as expectativas desta nova geração, ao mesmo tempo em que oferece caminhos para aprofundar os conhecimentos através das ofertas dos itinerários formativos o que também oportuniza aos estudantes o favorecimento e fortalecimento do protagonismo juvenil. A escolha do Itinerário também implica na escolha do currículo e nas áreas de futura atuação desses jovens. Por isso reforça-se a importância de construir um currículo no qual esse jovem se identifique, contribuindo para uma melhor aprendizagem e qualidade de ensino.

Os novos arquétipos determinados pela Base Nacional Curricular Comum (BNCC) forçam a escola a assumir uma cultura com foco na formação docente, afinal os professores precisam conhecer a proposta da BNCC para compreender os padrões estabelecidos por ela, pois isso influenciará todo processo educacional.

Ao tomar com objeto de análise a formação continuada realiza-se uma reflexão sobre a prática docente e nota-se que ela a partir de um determinado período recente da docência essa mudança tem sido uma constante. Em relação a isso se afirma que "enfim, cada vez mais os estudos sobre os saberes docentes vêm se constituindo como possibilidade de análise de processos de formação e profissionalização dos professores" (TARDIF, 2000, p.67).

A formação continuada do professor se desvela ao longo da sua trajetória e carreira profissional e, portanto, ao longo desse período muitas coisas vão sendo 
modificadas e aprimoradas. É esse diferencial que demonstra o docente envolvido e empenhado a fazer as coisas darem certo através de uma prática ressignificada, visto que:

\begin{abstract}
A formação não se constrói por acumulação de cursos, de conhecimentos ou de técnicas, mas sim através de um trabalho de reflexividade crítica sobre as práticas e de (re)construção permanente de uma identidade pessoal. Por isso, é tão importante investir a pessoa e dar um estatuto ao saber da experiência (NÓVOA, 1995, p.21).
\end{abstract}

Muitos fatores podem ser considerados como entrave para a realização da formação continuada. O tempo pode ser considerado como fator que dificulta 0 processo formativo, pois muitos docentes para sobreviver e ter uma qualidade de vida melhor trabalham em duas ou mais escolas. Some-se a isso o fato de muitas vezes em municípios diferentes e que exigem um deslocamento por meio de transporte público e no final do dia estão cansados. Dessa forma já contabilizamos até aqui três entraves.

O fator financeiro também pode se converter em um entrave, porque apesar da Constituição, da Lei de Diretrizes e Bases (LDB) e do Plano Nacional de Educação (PNE) mencionar a preocupação com a formação desse professor muitas vezes ele tem que pagar para obter formação. E como o salário do docente varia muito de acordo com a localidade muitos que começam acabam desistindo. $O$ fator financeiro, portanto, também pode ser incluído como empecilho. Ressalte-se que ainda de pagar a mensalidade há ainda despesa com transporte e alimentação.

Outra possibilidade surge do vínculo empregatício de professor que geralmente a depender da estrutura do município realiza-se processo seletivo, contrato ou regime administrativo. Muitos deles também podem atrasar salário ou simplesmente destruir o professor da sua função. Com isso o profissional não tem segurança então como pode se comprometer a realizar uma formação se na maioria das vezes ele tem que se deslocar para buscar conhecimentos?

A carga horária desse professor nas escolas nas quais trabalham dificulta que esse docente realize uma formação. Escalar o professor para ter formação no dia de sábado, por exemplo, ou em dias e horários nos quais ele não trabalhe naquela escola. O uso de tecnologias para a formação também pode se converter em um desafio para desistir de realizá-las. E por fim a própria formação continuada pode ser um entrave quando não atende a necessidade do professor ou mesmo o seu fim.

As expectativas em torno da formação são muitas e diversas, pois a proposta da formação quando bem construída e alinhada às particularidades daquela escola 
traz um bem-estar, o profissional sente-se reconhecido e valorizado. Sente-se preparado e isso implica em mudanças na sua prática em sala de aula. Quando a formação é realizada no momento em que ele está disponível na escola e não nos finais de semana ou dia em que não seja seu dia de trabalho.

\section{O Professor Que a Escola Tem e o Professor Que o Novo Ensino Médio Quer}

A educação com fins catequéticos atendendo as determinações políticas da época. Ao longo do aprimoramento da profissão até chegar aos dias atuais à educação segue fortemente influenciada pelas conjecturas político-econômicas. No qual está inserido o professor que traz em sua base a reflexão.

E falando no docente que é o responsável em pôr em funcionamento essa engrenagem do Novo Ensino Médio.... Quem é ele? Qual é o perfil desse profissional? Quem é o professor que a escola tem? Que professor o Novo Ensino Médio exige? Que impactos a formação continuada e em serviço desse profissional tem para a escola e para o contexto educacional?

Antes de responder as questões acima é preciso que retornar à história da educação a fim de conhecer a trajetória do professor, profissional presente no contexto político, econômico, social, cultural ao longo do tempo e da história da sociedade brasileira. No período em que o Brasil era Colônia, a educação desenvolvida pelos Jesuítas é voltada para aspectos religiosos e posteriormente de educar a sociedade. Para "educar" os habitantes dessa sociedade era preciso educá-los através da fé e de valores morais. O Instrutor, o professor aquele responsável em transmitir conhecimentos deveria possuir qualidades específicas aprovadas pela companhia de Jesus assim sendo,

Os professores representavam a possibilidade, por seu trabalho vivo na escola, do nexo fundamental entre instrução e educação, na medida em que fossem conscientes tanto dos contrastes entre o tipo de sociedade e de cultura representada pelos alunos - entendida como ausência de civilização quanto de sua tarefa, que consistia em propiciar uma inclusão por meio da formação disciplinada dos futuros homens e cidadãos (MATTOS, 1990, p.267).

O profissional destinado às atividades docentes neste período deveria apresentar alguns pré-requisitos necessários que o tornaria apto para o exercício na função de educar o homem desenvolvendo os valores morais primordiais para aquela sociedade. São eles: as regras, o caráter e a eloquência. O instrutor deveria reunir esses três predicados essenciais que regularizavam a educação neste 
período. O professor deveria saber comunicar-se de forma eficiente e eficaz, capaz de persuadir qualquer indivíduo. Deveria ensinar a lição, mas também fazê-los obedecer, seguir as normas e por fim o caráter ilibado de "dar conta de três coisas essenciais que então resumiam e normalizavam toda a educação: os preceitos, o estilo e a erudição" (HANSEN, 2000, p.26).

Já o docente do período Imperial não era diferente do período anterior tinha que ter um caráter moral imaculado. Ainda sim precisava possuir as seguintes características: controle, vigilância e estímulo. O professor neste período deveria garantir a educação e aprendizagem dos conteúdos valendo-se do uso da pedagogia moral. Esta educação funcionava por meio da utilização de comandos. Da mesma forma que no período anterior ainda não pode falar sobre profissionalização do professor

A política educacional brasileira foi sendo construída de forma lenta e como não podia ser diferente vinculada à política vigente em cada período. E enfim no ano de 1930 começa a evoluir, porém de forma como vimos não consegue acompanhar as mudanças da sociedade e a se desvencilhar de técnicas arcaicas e escolhas que não contemplam a realidade e a diversidade de questões no qual o país se encontra imerso.

No período republicano o professor apresenta aspecto civilizatório e um perfil cívico patriótico com bases científicas. A sua atuação docente é marcada por uma determinação a qual deve ser seguida de forma rígida desde o estabelecimento prédefinido dos conteúdos, materiais adequados e uma forma pré-estabelecida para ensinar e transmitir os conhecimentos.

A reforma do Novo Ensino Médio inicialmente enche de expectativas, mas posteriormente transformam-se em angústia ao pensar no prédio, na estrutura física das escolas que são rudimentares e não atendem as necessidades do ensino médio que existe atualmente. A proposta da escola integral está na contramão da estrutura escolar existente, pois:

O conceito de educação integral com o qual a BNCC está comprometida se
refere à construção intencional de processos educativos que promovam
aprendizagens sintonizadas com as necessidades, as possibilidades e os
interesses dos estudantes e, também, com os desafios da sociedade
contemporânea (BRASIL2018, p.14)

A maioria das escolas espalhadas pelo país não possuem infraestrutura para uma educação integral. Carecem de refeitórios, laboratórios, bibliotecas, auditórios, quadras poliesportivas, banheiros adequados à nova realidade educacional, salas de 
aulas espaçosas, bem ventilada e iluminada, equipadas com as tecnologias consideradas necessárias para que o professor exerça sua função e promova o desenvolvimento das habilidades e competências propostas.

Implantar as propostas da Base Nacional Curricular Comum (BNCC), na escola tem sido uma tarefa árdua e desafiadora. Pensar num currículo escolar que forneça os subsídios necessários ao processo de ensino aprendizagem do estudante de forma a preservar, reforçar as características da escola e da comunidade na qual estão inseridas exige uma mobilização enorme de conhecimentos por parte da gestão, coordenação pedagógica (quando se tem) e professores. Este último é objeto de estudo por parte de vários estudiosos, e por esta razão:

\begin{abstract}
Escreve-se muito sobre o professor que queremos, sobre como formá-lo e assumi-lo, como se estivéssemos diante de um profissional sem história. Um modelo novo a ser feito e programado. Um profissional que podemos fazer e desfazer a nosso belprazer; com novos traços definidos racionalmente pelas leis do mercado, pelas novas demandas modernas. Ou até pensamos podermos ser o professor que queremos, que sonhamos. É só constituí-lo em constituintes. Programá-lo, discutir seu perfil progressista, crítico. Tracemos um novo perfil e ele se imporá como um modo de ser daqui pra frente... [...] Ignora-se que o ofício de mestre educação primária, fundamental, básica carrega uma longa história. É uma produção social, cultural que tem sua história (ARROYO, 2008, p.38).
\end{abstract}

Pensar em cada proposta dos itinerários formativos é bastante trabalhoso, principalmente com uma clientela exigente, diversificada, com interesses diversos e conectada (aqueles que residem nos grandes centros urbanos). É preciso que os docentes da escola tenham formação e habilitação nas respectivas áreas de conhecimento e, além disso, eles precisam de uma formação permanente e em serviço sobre esta modalidade para que o trabalho desenvolvido em sala de aula atinja as exigências explicitadas pela Base.

As instituições públicas brasileiras de ensino possuem um corpo docente habilitado para o exercício docente. São homens e mulheres licenciados nas mais diversas áreas do conhecimento do Ensino superior. Ressalta-se aqui que muitos desses docentes são frutos da Politica Pública de Formação de professores. A maioria desses profissionais tem curso de especialização na área de formação e alguns cursos de formação continuada.

Muitos desses profissionais trabalham em outros espaços escolares para suprir suas necessidades básicas, pois os proventos pagos a esses profissionais a depender da localidade estão abaixo do que determina o piso nacional dos docentes e longe do ideal. Como grande parte das escolas públicas brasileiras os docentes 
comprometidos desenvolvem suas atividades utilizando o que é possível, as ferramentas que estão ao seu alcance como livros didáticos e apostilas, quadro e aulas expositivas "[...] numa pedagogia que valoriza a ação de ensino por parte do professor, como naquela em que o professor é visto como um mediador da aprendizagem do aluno" (DEVELAY, 1995, p.41).

Ainda que se trabalhe com aulas expositivas, as aulas são dialógicas e provocativas. Os alunos são levados a refletir e a debater. O professor leva o aluno a participar, a interagir nas aulas por meio de situações problemas. Ao final da aula os alunos são convocados a construir e apresentar soluções viáveis na resolução dos problemas relacionados às questões propostas. Há uma necessidade incessante de redimensionar nosso trabalho pedagógico e, portanto, o profissional precisa procurar novas bases para subsidiar sua prática no intuito de obter um ensino, aprendizagem eficiente. Nessa era tecnológica a ação do professor ganha novos contornos e as mais variadas dimensões.

O professor mostra-se competente e habilidoso em circunstâncias intricadas que exijam experiência na resolução de problemas práticos que exigem saídas criativas integrando técnica e conhecimento. O pensar, o refletir remete ao aspecto identitários do professor, favorecendo o diálogo isto é uma atividade reflexiva. A profissão de professor exige-se sabedoria apurada, certa propriedade com as teorias pedagógicas que embasam nossa prática. [...] "a reflexão crítica sobre a prática se torna uma exigência da relação Teoria/Prática sem a qual a teoria pode ir virando blá, blá, blá e a prática, ativismo" (FREIRE, 1996, p.22).

Em meio a tantas transformações pelas quais a sociedade vem passando e atualmente influenciada pelas tecnologias que passaram a fazer parte do cotidiano dos quais todos nós estamos inseridos. A atual configuração social suscita da escola um profissional com habilidades e conhecimentos diversos para atuarem nas várias frentes do campo educacional.

O perfil do docente para atuar no Novo Ensino Médio requer que o mesmo seja um profissional que conheça e domine com profundidade o seu campo de conhecimento. Esse novo professor que passa a exercer múltiplas funções: mentor, pesquisador, promotor de práticas inovadoras sustentáveis e de empreendedor. É o profissional capaz de compreender, conhecer e dominar toda essa nova realidade social marcada pelas novas tecnologias. Também faz uso de materiais de acordo com as competências expressas pela Base Nacional Curricular Comum (BNCC). 
O professor é o profissional que questiona enxerga além do básico, ele vê o todo e não partes. Ele pensa diferente, ouve, compreende o estudante como protagonista do processo de ensino-aprendizagem. Procure estabelecer diálogo e transmite segurança

As competências sócioemocionais (autogestão, autoconsciência, consciência social, habilidade de relacionamento, tomada de decisão responsável) estão diretamente ligadas às emoções dos indivíduos faz-se necessário que o professor saiba lidar com estas questões, uma vez que:

\begin{abstract}
A atividade docente se caracteriza também por uma grande complexidade do ponto de vista emocional. Os docentes vivem num espaço carregado de afetos, de sentimentos e de conflitos. Quantos prefeririam não participar disso? Mas eles sabem que um tal distanciamento seria a negação do seu próprio trabalho (NÓVOA 2008, p.229).
\end{abstract}

Além de dominar as ferramentas tecnológicas, o professor deve fazer uso constante desses instrumentos pedagógicos com vistas ao enriquecimento, incrementação dos conhecimentos na sala de aula. Utiliza os recursos digitais para enriquecer as aulas. É o profissional que compreende as novas formas de interação (linguagem/comunicação) e que domina essas novas ferramentas de linguagem. E que faz uso desse processo comunicativo envolvendo os estudantes e por esse motivo:

A forma de ser do professor é um todo e dependente, certamente, da cosmovisão que ele possui. Não sei até que ponto é importante ou possível classificar as atitudes dos professores. Até porque também elas, como fruto da contradição social, nem sempre apresentam formas lineares e totalmente coerentes com uma corrente filosófica. É inegável, porém, que a forma de ser e de agir do professor revela um compromisso. E é esta forma de ser que demonstra mais uma vez a não-neutralidade do ato pedagógico (CUNHA, 1998, p.70).

O professor que a escola tem na atualidade diferentemente daqueles que precederam este ofício devem possuir formação superior nos diversos campos e áreas de conhecimentos das licenciaturas. A sua prática docente hoje é constantemente revisada e ressignificada, uma vez que os docentes se deparam com novas circunstâncias as quais requerem mudanças de posturas e paradigmas, assim sendo:

Um bom docente é aquele que se torna não-indispensável, que consegue que seus alunos aprendam sem a sua ajuda. Assim, os docentes desmitificam o seu próprio saber e entregam a fonte do poder ao cliente, o que outras profissões guardam zelosamente (LABARE 2000 apud NÓVOA, 2008,p.232). 
Como a maioria das escolas da rede pública de ensino não dispõe das tecnologias necessárias para o trabalho pedagógico na escola, os docentes fazem uso daquilo que se encontra mais fácil: os smartphones e a televisão com entrada USB. Não é a ferramenta ideal, mas é aquela que temos ao nosso alcance e a qual pode tornar a aula mais atrativa. Com a televisão se pode trabalhar vídeos, filmes, músicas, clipes, imagens de uma determinada temática ou assunto. Os docentes muitas vezes fazem o possível e o impossível para que os estudantes tenham acesso aos conhecimentos necessários a sua formação e também o desenvolvimento das suas habilidade e competências.

O fato da maioria dos docentes não dominarem as ferramentas tecnológicas e não terem acesso às ferramentas educacionais adequadas para utilizarem sem suas aulas isso não quer dizer que suas aulas são insossas. Na verdade, mesmo não tendo acesso aos aparatos tecnológicos educacionais, os professores buscam opções criativas a fim de proporcionar aulas diferenciadas que promovam o conhecimento aos estudantes sejam através do engajamento em projetos, aulas de campo, gincanas, feiras de conhecimentos, seminários temáticos, jogos e tantas outras formas criativas que corroboram para o êxito do processo de ensino aprendizagem.

\section{As Tecnologias Educacionais}

A mudança educacional propostas pela reforma do ensino médio chegou ao seu ápice com a construção da Base Nacional Curricular Comum (BNCC) que dispõe os itinerários formativos. A nova configuração da nova modalidade prima pelo direito à educação considerando o fomento e desdobramento das aprendizagens por meio das habilidades e competências.

Durante o processo de execução do Novo Ensino Médio ocorreu a construção do novo desenho do currículo que deve estar alinhado as determinações explicitadas pela BNCC que contemplem os aspectos sócioemocionais, o redimensionamento do papel do professor e sua prática pedagógica fazendo uso das novas tecnologias educacionais com vistas a melhora da qualidade de ensino nacional. A quinta competência estabelece que seja necessário:

Compreender, utilizar e criar tecnologias digitais de informação e comunicação de forma crítica, significativa, reflexiva e ética nas diversas práticas sociais (incluindo as escolares) para se comunicar, acessar e disseminar informações, produzir conhecimentos, resolver problemas e exercer protagonismo e autoria na vida pessoal e coletiva (BRASIL, 2018, p.9) 
No decorrer da história da humanidade, o homem, viu-se obrigado a se reinventar para sobreviver. E para que pudesse sobreviver teve que desenvolver estratagemas utilizando sua inteligência e os conhecimentos. Desenvolveu a arte da dominação assim descobriu o fogo, a roda, ferramentas, armas, armaduras, escudo, produtos e do mesmo modo propiciou o desenvolvimento das tecnologias, pois "o domínio de determinados tipos de tecnologias, assim como o domínio de certas informações, distinguem os seres humanos" (KENSKI, 2012, p.15).

Em um mundo globalizado, onde as mudanças e evoluções encontram-se arraigados no seio da sociedade é preciso evoluir e adaptar-se cada vez mais rápido a fim de acompanhar os avanços tecnológicos. A escola não pode estar indiferente a este processo, já que, ela retrata a coletividade atual, e também por ser um espaço de formação.

É inegável o fato de que as novas tecnologias inúmeras mudanças para as instituições educacionais, ou melhor, as salas de aulas e impulsionou o processo de ensino e aprendizagem. A tecnologia educacional pode ser compreendida como o uso de recursos tecnológicos com propósitos pedagógicos que enriqueçam as aulas com práticas inovadoras intensificando o processo de ensino aprendizagem, pois "as maneiras, jeitos ou habilidades especiais de lidar com cada tipo de tecnologia, para executar, ou fazer algo, chamamos de técnicas" (Ibid., p.24)

O grande obstáculo que encontramos para o emprego, uso das tecnologias educacionais é a dificuldade em acessá-la principalmente por todos os profissionais que exercem seu ofício nas escolas públicas as quais são frequentadas por indivíduos da classe social com menor poder aquisitivo. Por outro lado, o que está em jogo aqui não é o uso dos equipamentos e sim sobre as inovações das práticas docentes possibilitadas por elas.

O professor deve definir o objetivo para só depois optar pelo recurso tecnológico mais apropriado. A desinformação, o desconhecimento sobre as múltiplas possibilidades que as tecnologias podem viabilizar pode se constituir em um entrave, uma resistência por parte dos educadores. Quais seriam os benefícios ao usar as tecnologias educacionais na escola?

As perspectivas ao utilizar as Tecnologias da Informação e Comunicação (TICs) na sala de aula são inúmeras, por exemplo, o favorecimento da troca de experiências, proporciona novas formas de interação, expande o acesso à informação, auxilia a comunicação, melhora o desempenho do aluno etc. Vale 
salientar "que o aprendiz seja participativo na construção do conhecimento. Assim, aprende-se dialogando, investigando, buscando possíveis respostas [...]" (MOTA, 2007, p.110).

Pensando na aquisição e das prováveis contribuições advindas da utilização das tecnologias em sala de aula, é importante que toda equipe pedagógica participe do processo de escolha das ferramentas mais adequadas considerando também as possibilidades de suporte e reparo para o produto. A capacitação/formação também é crucial primeiro para que se conheça e depois para manusear e usar de forma correta. As escolhas das tecnologias a serem adotadas pela unidade escolar precisa considerar a quantidade a ser comprada e demais componentes necessários para que ele funcione.

Não há como fugir das tecnologias, elas estão aí e a sua inclusão bem como os materiais didáticos digitais em sala de aula assinala a entrada da escola nesse mundo digital, aos quais as informações, conhecimentos circulam com muita rapidez e agilidade. E como diria Fernando Pessoa "Navegar é preciso!" Mais do que navegar é conveniente saber navegar.

\section{Considerações Finais}

O Novo Ensino Médio traz vários desafios para os educadores, para os educandos, para a escola. A escola precisa adequar sua estrutura física, o projeto político pedagógico, o currículo, equipamentos e materiais pedagógicos pertinentes. Os discentes terão a oportunidade de desenvolver seu projeto de vida, ser protagonista, desenvolver as habilidades e competências propostas bem como outros aspectos relativos a aprendizagem. O docente precisa ser flexível e assumir vários papeis, fazer a inserção de tecnologia em suas aulas e participar de formações continuadas.

Dessa forma percebe-se que o professor ante ao atual contexto carece de formação contínua para estar preparado para as situações que desembocam na escola e assim ofertar a comunidade escolar uma educação de qualidade. A formação continuada em serviço tende promover ao educador a obtenção de instrumentos que o auxilie a suplantar as adversidades que surgem na sua ação pedagógica concreta

A formação continuada docente vem se mostrando importante para o processo da educação independentemente do nível (pré-escola, fundamental, 
médio ou superior), pois auxilia o docente a aprimorar as práticas pedagógicas e isso influencia significativamente a qualidade de ensino e para vários autores encontra-se atrelada ao desempenho do professor. Nota-se que a formação continuada, contínua e ou permanente não importa a nomenclatura, o que interessa é que ela proporciona o aperfeiçoamento dos conhecimentos fundamentais para as atividades pedagógicas tendo em vista a qualidade de ensino.

Ao refletir sobre a importância da formação continuada é preciso compreender a complexidade do ofício de professor atualmente uma vez que a sua função tem sido desvirtuada e outros papeis Ihes são imputados. Por essa razão faz-se necessário refletir acerca de uma formação continuada que valorize o docente e que ao mesmo tempo possa articular a teoria com a prática. Ela mostrase importante na construção do processo ensino aprendizagem pois nos permite refletir sobre nossa prática. A atualização docente é necessária para que compreendamos e ao mesmo tempo refletir sobre o processo evolutivo e desenvolver as habilidades necessárias para lidar com as questões que se apresentam no cotidiano escolar.

No atual contexto impulsionado pelos avanços científicos e tecnológicos é imprescindível que os profissionais da educação estejam inteirados, atualizados e preparados para responder as demandas de questões que eclodem no ambiente escolar. Por meio da formação continuada o docente obtém conhecimento e promove mudanças na sala de aula em busca de alternativas para a melhora do processo ensino adotando as estratégias adequadas para promover o protagonismo do aluno, promovendo um trabalho interdisciplinar, fomentando a aprendizagem compartilhada, sensibilizando o educando para conscientização, estimulando o pensamento crítico e utilizando as ferramentas tecnológicas para o fomento da prática de pesquisa.

\section{Referencias}

ANDRÉ, M. (org). Práticas inovadoras na formação de professores. CampinasSP: Papirus, 2016.

ARROYO, M.G. Ofício de mestre: imagens e auto-imagens. Petrópolis, RJ: Vozes, 2008.

BRASIL. Base Nacional Curricular Comum. Brasília. 2018. Disponível em: http://basenacionalcomum.mec.gov.br/ Acessado em maio de 2020 
CUNHA, M.I. O bom professor e sua prática. Campinas, SP: Papirus,1998.

CURY, C.R.J.. et al. Base Nacional Comum Curricular: dilemas e perspectivas. São Paulo. Cortez. 2018

DEVELAY, M. Savoirs scolaires et didactique des disciplines: Une encyclopédie pour aujourd'hui. Paris: ESF Editeur, 1995.

FREIRE, P. Pedagogia da autonomia: saberes necessários à prática educativa. São Paulo: Paz e Terra, 1996.

GASPARIN, J. L. Uma didática para a pedagogia histórico-crítica. Campinas: Autores Associados, 2011.

HANSEN. J. A.. A civilização pela palavra. IN: LOPES; FARIA FILHO; VEIGA (orgs.). 500 anos de educação no Brasil. Belo Horizonte: Autêntica,2000.

KENSKI, V. M.. Educação e Tecnologias: 0 novo ritmo da Informação. 8 ed.Campinas-SP: Papirus, 2012.

LIBÂNEO, J. C.; Pedagogia e pedagogos: inquietações e buscas. Educar, Curitiba: Editora da UFPR, 2001.

MARIN, A. J. Didática e trabalho docente. Araraquara: Junqueira e Marin, 2005.

MATTOS, I. R. O Tempo Saquarema. a formação do estado imperial. 2. ed. São Paulo: Hucitec, 1990.

MOTA, J. A presença do afeto no cenário pedagógico. Dissertação (Mestrado em Educação).Brasília: Universidade de Brasília. Faculdade de Educação. 2007

NÓVOA, A. Os professores e o novo espaço público da educação. In: TARDIF, M.;LESSARD.C. $O$ ofício de professor: histórias, perspectivas e desafios internacionais. Tradução de Lucy Magalhães. Petrópolis, RJ: Vozes, 2008.

NÓVOA, A. (org.). Os professores e sua formação. Portugal: Dom Quixote: 1995

PIMENTA, S. G (org.). Formação de professores: identidade e saberes da docência. In: PIMENTA, S. G. Saberes pedagógicos e atividade docente. 6 ed. São Paulo: Cortez, 2012.

PINTO, A. V. Sete lições sobre educação de adultos. São Paulo: Cortez, 1989.

SAVIANI, D. Pedagogia Histórico-Crítica: Primeiras Aproximações. 8. ed. Campinas/Autores Associados, 2003

TARDIF, M. Ambiguidade do Saber Docente nas Reformas Relativas à Formação Universitária para o Magistério. 2000. 